\title{
Early exposure to hands-on surgical training encourages urological interest in undergraduate medical students
}

Tomokazu Kimura ( $\boldsymbol{\nabla}$ tomokazu.kim@md.tsukuba.ac.jp )

University of Tsukuba

Kosuke Kojo

University of Tsukuba

Atsushi lkeda

University of Tsukuba

Shuya Kandori

University of Tsukuba

Takahiro Kojima

University of Tsukuba

Junji Haruta

University of Tsukuba

Hiroyuki Nishiyama

University of Tsukuba

Research article

Keywords: early exposure, urology, surgical skills, career choice

Posted Date: March 31st, 2020

DOl: https://doi.org/10.21203/rs.3.rs-19513/v1

License: (c) (i) This work is licensed under a Creative Commons Attribution 4.0 International License.

Read Full License 


\section{Abstract}

Background: Urological education is as important as surgical training for undergraduates. However, those in undergraduate medical schools have less exposure to surgery and urology as their curriculum focuses more on clinical skills, particularly community-based healthcare for a super-aging society. This study aimed to evaluate whether urologic hands-on training could encourage surgical and urological interest in medical undergraduate students.

Methods: A one-day elective program in urologic surgery at the University of Tsukuba, particularly in robotic, laparoscopic, and endoscopic surgeries, was offered to 58 fourth-year medical students in 2018 and 2019, prior to their clinical clerkship. The average age of participants was 22 (range: 21-25) years. We assessed scores (1-5 Likert-type items) in training activity, interest in surgery, and interest in urology before and after the course.

Results: Before attending the program, average scores in interest in urology were 3.53 in 2018 and 3.15 in 2019. After training, the total likely scores of this program in 2018 and 2019 were 4.59 and 4.76, respectively. The likely scores in surgery increased after the program; however, this was not significantly different to that prior to the program. However, the average interest scores in urology were significantly increased to $3.91 \pm 0.63(p<0.05)$ and $3.88 \pm 0.58(p<0.01)$ in 2018 and 2019 , respectively, indicating a motivation to pursue surgery and urology following clinical clerkship, 1 year after training.

Conclusions: Urological hands-on training facilitated interest in urology in medical students prior to their clinical clerkship. Early experience in actual urological procedures could encourage medical students to consider specializing in urology and pursue a career as a urological specialist.

\section{Background}

Medical school provides an opportunity to not only acquire the knowledge and skills but also experience in various specialties. Medical students in lower years of study, study and learn with the help of classroom lectures and other recently adopted clinically-oriented teaching methods ${ }^{1}$. After gaining basic medical knowledge, they learn skills through a rotating clinical clerkship over a period of 6 years after graduating from high school in Japan ${ }^{2}$. In addition to subject knowledge, medical students must learn the required attitude and skills that make them qualified to meet the needs of citizens ${ }^{3}$. In Japan, upcoming medical doctors should have clinical skills, especially in community-based health care for the super-aging society ${ }^{4}$. Thus, medical schools are modifying their curriculum to consider these societal needs. Thus, medical students obtain less experience in surgical subjects than in other essential medical specialties such as internal medicine, psychology, and primary healthcare ${ }^{5}$. To bridge this increasing gap in knowledge, several surgical departments have been trying to teach surgery more efficiently in an educational program (such as simulation-based learning) during clerkship. 
Simulation-based learning is broadly used in medical schools globally. Simulation is very useful for beginners to learn invasive procedures, including the physical examination, puncture procedures, and emergency treatment ${ }^{6}$. To achieve better outcomes with simulation-based education, the following factors need to be considered: range of difficulty, repetitive practice, distributed practice, cognitive interactivity, multiple learning strategies, individualized learning, mastery learning, feedback, length of training, and clinical variation ${ }^{7}$. For expert training, more novel challenges are recommended. However, this adds to the financial cost and burden of faculties as simulation equipment is expensive and requires that instructors put in extra work. Nevertheless, simulation-based education is effective in imparting basic science and clinical knowledge and improving procedural skills, teamwork, and communication skills in undergraduate and graduate medical students ${ }^{8}$.

Choosing a specialty is one of the most important decisions for medical students ${ }^{9}$. In Japan, postgraduates rotate through several specialties within two years as junior residents before starting their training in their selected specialty ${ }^{2}$. Medical students and junior residents choose their specialty based on a variety of factors, including medical lifestyle, societal orientation, hospital orientation, scope of practice, and the impact of role model ${ }^{10}$. Compared to any other specialty, urology is less popular among medical students due to the misconception that urologists are generally male organ specialists ${ }^{11}$. A urologist deals with the entire genitourinary system of men and women. Moreover, the need for female urologists has increased over the past 10 years $^{12}$. Medical students' misunderstanding of urology will remain uncorrected unless they are exposed to the correct clinical circumstances. Students are more likely to be influenced to pursue surgical careers if they are offered early exposure to positive role models and career and academic opportunities ${ }^{13}$. Thus, early involvement of medical students may provide ideal opportunities or mentored externships for recruitment, not only in urology but also in other departments.

The school of medicine at the University of Tsukuba has given an "advanced course" to fourth-year medical students prior to starting their clinical clerkship. This short course consists of intensive lectures based on the concept of exposing pre-clinical clerkship students to recent, focused, and advanced medical issues. Several professors offer lectures on various disciplines such as basic science, medical statistics, internal medicine, psychology, surgery, anaesthesia, social medicine, and space medicine. Each student can select several courses in their fields of interest over one week. Our urology department has given hands-on seminars on endoscopic, laparoscopic, and robotic surgeries since 2012. Students who had attended this course were motivated to learn about surgery and were more interested in urology.

We hypothesized that specific factors could contribute to urological and surgical experience and that a positive experience would be associated with students' interest in a career in not only surgery but also in urology. This study evaluated whether this urology course, designed to provide the required exposure to medical students, could cultivate an interest in surgery and urology among pre-clinical clerkship medical students.

\section{Methods}




\section{Course design}

A one-day elective course focused on hands-on training in urologic surgery, particularly robotic, laparoscopic, and endoscopic surgeries, was offered to fourth-year medical students of the University of Tsukuba in 2018 and 2019. Participants were separated into three groups. Subsequently, each group rotated through endoscopic procedures, laparoscopic suturing, and robotic surgery, respectively, over 2 hours (Fig. 1). The grouped students were further separated into four subgroups rotating through endoscopic workshops lasting for 30 minutes each, including cystoscopy, transurethral resection, laser prostatectomy, and transurethral lithotripsy (Fig. 2).

In the robotic surgery course, students used the DaVinci skills simulator of preinstalled tasks including "Endo Wrist Manipulation", "Energy and Dissection", and "Needle Control and Driving”. In the laparoscopic course, the students were trained in suturing skills using string with a needle in a dry box. Meanwhile, the students in the endoscopic course were divided into 4 groups: transurethral resection (TUR), photoselective vaporization of the prostate (PVP), cystoscopy, and transurethral lithotripsy (TUL). During the TUR session, the students cut into a konjac plate (a jelly-like food made from the starch of the konjac potato) under a saline pool using the TUR system. During the PVP session, the laser vaporization procedure was demonstrated to students using a PVP simulator. During the cystoscopy session, students performed the cystoscopy procedure using a flexible cystoscope on a flask, which resembled the urinary bladder. During the TUL session, students used a flexible ureteroscope and basket forceps to remove simulated renal stones out of a urinary tract model.

\section{Evaluation}

Before the start of training, the participating students were asked to provide their demographic information in a pre-course survey. Moreover, they provided a self-assessment (1-5 Likert-type items) on their interests. They checked the " 5 " score when they were very interested, while a "1" was scored when they were not interested at all. After the training, the participating students and faculty members were made to answer a post-course survey in which they were able to provide a free description to the questions. To evaluate the long-term effect of the course, we used a web questionnaire on participating students. Evaluation of the participating students was performed 3 months after having taken the course in 2018. Conversely, the evaluation done in 2019 was performed after 1 year. The questionnaire was the same as the provided self-assessment (1-5 Likert-type items) and free description surveys.

\section{Assessment}

Data for these evaluations were collected from all students enrolled in the course who completed the preand post-course surveys. We analysed the mean difference in the interest score in surgery and urology before and after the program using paired t-tests in 2018 and 2019. All data analyses were performed using JMP14 and Microsoft Excel®. Descriptive statistics, chi-square test, or Fisher's exact test were used, as appropriate. We also analysed the answers obtained from the free description section of the questionnaire. 


\section{Results}

Two-hundred and twenty-two medical students have selected to enrol in our course since 2012. Of these, 32 and 26 students took part in this course in 2018 and 2019, respectively (Table 1). The average age of participants was 22.2 (range: 21-24) years and 22 (range: 21-25) years in 2018 and 2019, respectively, among approximately 140 medical school fourth-year students. Overall, $34.4 \%$ and $38.5 \%$ of participants were female, respectively. Eleven urology faculty members including two female urologists and several staff members from the medical equipment company helped teach the workshops.

Table 1

Background characteristics of participants

\begin{tabular}{|c|c|c|c|c|c|c|}
\hline \multirow{2}{*}{$\begin{array}{l}\text { Fiscal year } \\
\text { No. of students }\end{array}$} & & \multicolumn{2}{|c|}{2018} & \multicolumn{2}{|c|}{2019} & P-value \\
\hline & & \multicolumn{2}{|l|}{32} & \multicolumn{2}{|l|}{26} & \\
\hline \multirow[t]{2}{*}{ Age } & Median & \multicolumn{2}{|l|}{22} & \multicolumn{2}{|l|}{22} & n.s. \\
\hline & Range & \multicolumn{2}{|c|}{$21-24$} & \multicolumn{2}{|c|}{$21-25$} & \\
\hline \multirow[t]{2}{*}{ Sex } & Male & 21 & 65.6 & 16 & 61.5 & n.s. \\
\hline & Female & 11 & 34.4 & 10 & 38.5 & \\
\hline \multicolumn{7}{|l|}{ Curiosity } \\
\hline & Internal medicine & 20 & 62.5 & 15 & 57.7 & n.s. \\
\hline & Surgery & 22 & 68.8 & 15 & 57.7 & n.s. \\
\hline & Urology & 14 & 43.8 & 5 & 19.2 & 0.044 \\
\hline \multicolumn{7}{|c|}{ Pre-course likely score } \\
\hline \multirow[t]{2}{*}{ Surgery } & Average & \multicolumn{2}{|c|}{4.12} & \multicolumn{2}{|c|}{4.00} & n.s. \\
\hline & SD & \multicolumn{2}{|c|}{0.148} & \multicolumn{2}{|c|}{0.111} & \\
\hline \multirow[t]{2}{*}{ Urology } & Average & \multicolumn{2}{|c|}{3.53} & \multicolumn{2}{|c|}{3.15} & 0.06 \\
\hline & SD & \multicolumn{2}{|c|}{0.149} & \multicolumn{2}{|c|}{0.613} & \\
\hline
\end{tabular}

Before attending the course in 2018, the average interest scores in surgery and urology were 4.12 and 3.53 , respectively. Those in 2019 were 4.00 and 3.15, respectively. Attending students were already interested in surgery but not in urology.

After training, robotic surgery was the most interesting to participants in both periods. Regarding laparoscopic suturing, single port surgery tended to have more of a "less likely" score than the 3dimensional and 2-dimensional classical laparoscopic procedures. Endoscopic procedures such as TUR, 
PVP simulation, cystoscopy, and TUL were also attractive to medical students. The comprehensive evaluation scores of this course in 2018 and 2019 were 4.59 and 4.76, respectively (Fig. 3)

Table 2 shows the difference in likely scores before and after the course. After attending the course, the likely scores in surgery were higher, but this difference was not significantly different to that obtained prior to the course in both years. Interestingly, those of urology were significantly increased compared to those of the pre-course. Particularly, the number of students who selected a score of 5 increased, and the number of students who selected a score of 2 decreased (Fig. 4). Free description questionnaire results showed that medical students became more interested in urology and surgery and felt motivated for their clinical clerkship. Faculty members found the teaching workload and burden of costs too high; thus, they placed their clinical practice ahead of teaching the course. However, they felt that the course was very important for medical students in addition to clinical practice.

Table 2

Likely scores of interest for surgery and urology before and after the course

\begin{tabular}{|c|c|c|c|c|c|}
\hline & & \multicolumn{2}{|c|}{ Surgery } & \multicolumn{2}{|c|}{ Urology } \\
\hline & & 2018 & 2019 & 2018 & 2019 \\
\hline \multirow[t]{2}{*}{ Average } & Before & 4.13 & 4.00 & 3.53 & 3.15 \\
\hline & After & 4.34 & 4.27 & 3.91 & 3.88 \\
\hline Effect size & & 0.18 & 0.35 & 0.35 & 0.72 \\
\hline Mean difference & & 0.22 & 0.27 & 0.38 & 0.73 \\
\hline Standard deviation & & 0.21 & 0.14 & 0.18 & 0.14 \\
\hline Upper 95\% & & 0.65 & 0.56 & 0.74 & 1.02 \\
\hline Lower 95\% & & -0.21 & -0.02 & 0.01 & 0.44 \\
\hline P-value & & 0.30 & 0.07 & 0.04 & 0.00 \\
\hline
\end{tabular}

To evaluate the long-term effect of this course, we performed a post-course web questionnaire, with 13 (40.6\%) students in 2018 and 17 (65.4\%) in 2019 completing the questionnaire. Table 3 shows the results of the long-term evaluation. Regarding memory, "Remember the course" maintained very high scores of $4.53 \pm 0.503$ months after the course and $4.62 \pm 0.491$ year after the course. Regarding the effect on learning during clerkship, this course played a significant role on the effect of learning both surgery and urology. However, the scores obtained for interest in surgery and urology gradually decreased over time (Fig. 5.). The average likely scores dropped to below 4 in surgery and below 3 in urology. 
Table 3

Long-term effect of this course

\begin{tabular}{|llllll|}
\hline & & 2018 & & 2019 \\
\hline & & Ave & SD & Ave & SD \\
\hline Remembering & Whole course & 4.62 & 0.49 & 4.53 & 0.50 \\
& Robotic surgery & 4.31 & 0.82 & 4.12 & 0.68 \\
\hline & Single port surgery & 3.54 & 1.08 & 3.47 & 0.98 \\
\hline 3-dimensional laparoscopy & 3.62 & 0.92 & 4.06 & 0.64 \\
\hline & Laparoscopic surgery & 4.54 & 0.63 & 4.12 & 0.90 \\
\hline & TUR & 3.85 & 0.86 & 2.65 & 0.84 \\
\hline & PVP & 3.85 & 0.95 & 3.24 & 1.06 \\
\hline Cystoscopy & 3.69 & 0.99 & 2.82 & 0.98 \\
\hline TUL & 3.77 & 0.89 & 3.00 & 0.97 \\
\hline Interested in & Surgery & 4.54 & 0.63 & 4.24 & 1.00 \\
\hline Affect the learning at clerkship & Urology & 3.54 & 1.01 & 3.24 & 0.55 \\
\hline Surgery & 4.15 & 0.77 & 4.35 & 0.76 \\
\hline Career selection & Urology & 4.23 & 0.70 & 3.88 & 0.68 \\
\hline transurethral lithotripsy, TUR: transurethral resection & 3.92 & 0.92 & 3.76 & 1.00 \\
\hline & Surgery & 2.85 & 1.03 & 2.47 & 0.61 \\
\hline
\end{tabular}

\section{Discussion}

According to this study, early exposure to urological hands-on training in pre-clinical clerkship students resulted in an increasing interest, especially in urology. Surgical training courses were generally conducted during clinical clerkship or postgraduate periods ${ }^{14}$. The most novel aspect of this study was conducting a hands-on course that focused on urological training in medical students prior to clinical clerkship.

Early exposure is an effective method for educating medical students in not only basic science but also clinical clerkship ${ }^{15,16}$. This study showed that hands-on training in urologic procedures impacted on preclinical clerkship medical students as it increased their interest in urology. However, this course did not 
increase the interest in surgery among students who already had an interest in surgery prior to the course. Thus, it was of limited value to those who showed an interest prior to the course. In contrast, this course made a good impression on students with regards to urology. Generally, there were more students interested in surgery than in urology at the beginning of the course. Moreover, what urologists do is relatively unknown to the public compared to what is done in surgery, internal medicine, paediatrics, and other specialties. The lesser-known specialities may be able to promote their specialty and the roles they play to medical students in their earlier years of training as well as the public. As medical students are rarely provided with experience in performing not only surgical procedures but also independent simulated surgeries prior to undergoing their clinical clerkship, this course could have a great impact on medical students prior to their clinical clerkship.

As a systematic review and meta-analysis showed that technology-enhanced simulation was more effective than instructional methods, actual experience could be beneficial for learners ${ }^{17}$. In this course, students could perform surgical procedures and use simulators for a certain amount of time under the supervision of several faculty members. Regarding endourologic skills, early feedback can be beneficial when learning through novel simulation training ${ }^{18}$. Thus, these experiences may encourage students to learn surgery and urology further following their clinical clerkship. However, numerous experiences may influence their choices because medical students must rotate through several subjects for a long period of time during their clerkship. Recently, motivation was found to be one of the most important factors for continuing learning in the field of medical education ${ }^{19}$. To maintain and improve the effect of the course, surgeons and urologists should continue offering students the opportunity to obtain surgical experience and the opportunities provided to them during their surgery and urology rotations should be performed using technical and educational approaches such as the motivational dynamic model ${ }^{19}$.

Early clinical experience as a degree on influence on the selection of a particular career by undergraduate students ${ }^{7}$. In Japan, medical students usually undergo a 2-year primary resident course followed by a 4year specialized medical course to pursue their career path ${ }^{20}$. The career chosen by medical students depends on their experiences since birth and their own prerogatives. Particularly, parental career expectations may also have an impact on their career choice ${ }^{21}$. However, for medical undergraduates, exposure to specialties and the timing of this exposure are crucial to career choice; this is true for any specialty 22 . Medical students should rotate through several departments during their clinical clerkship, although not through all departments. Most medical school curriculums tend to focus on good clinical practitioners who are trained to care for a super-aging society; thus, the time spent rotating through surgical departments is likely to decrease. This limits the exposure of students, particularly those with an interest in surgery, to non-essential subjects. Several medical experts have been trying to recruit young doctors and medical students in Japan as junior residents are able to select their specialty of choice freely. As there are several reports showing that short courses and surgical simulations could influence their choice in career specialty, early exposure to surgical subspecialties could influence students to pursue a career in these fields ${ }^{23-26}$. In contrast, several surgical departments showed that early surgical exposure increased their understanding and interests; although, it did not affect their career choice ${ }^{27}$. 
Regarding urology, only a limited number of medical schools require a formal educational rotation in urological surgery; thus, medical students perceive their knowledge of urology as poor even when medical students are aware of urology as a specialty ${ }^{28}$. In contrast, clinical performance during a rotation at their school is the most important factor taken into account when choosing future urology residents ${ }^{29}$. Regarding timing, a report showed that third-year medical students were more likely to consider urology than final-year students due to multifactorial reasons ${ }^{30}$. Extrinsic and intrinsic motivation was correlated with several factors such as being female, personal choice, and positive attribute of determination ${ }^{31}$. Accordingly, this early exposure course, provided during fourth year, could be an effective initiation to a urological career for medical students prior to clinical clerkship.

This study has several limitations. First, the number of students was small because this course was conducted by a single urology department at a medical school. Second, although an increase in scores for surgery and urology were found, we only evaluated the change in likely scores before and after the course. However, we did not compare this to a control group. Third, as students had not yet graduated and selected their specialty, the true outcome could not be evaluated, Further long-term studies are required to determine whether the course results in graduates selecting surgical or urological specialties. However, this study found that early exposure to hands-on training in urology increased students interest in urology. This course may be used by other departments to encourage students to learn or take up their specific specializations.

\section{Conclusions}

Urological hands-on training encouraged interest in urology among medical students prior to their clinical clerkship. Early experience in actual surgical techniques could motivate students to learn about surgical specialities during their clinical clerkship as well as encouraging them to pursue a career in a surgical specialty.

\section{Abbreviations}

PVP, photo-selective vaporization of the prostate

TUL, transurethral lithotripsy

TUR, transurethral resection

\section{Declarations}

\section{Ethics approval and consent to participate}

This study was approved by the Ethics Committee at Medical school, University of Tsukuba (approval number 19-1394). The study participants provided written informed consent. 


\section{Consent for publication}

Not applicable.

\section{Availability of data and materials}

The datasets used and/or analysed during the current study are available from the corresponding author on reasonable request.

\section{Competing interests}

The authors declare that they have no competing interests.

\section{Funding}

No funding was received for this study.

\section{Authors' contributions}

TKi analyzed and interpreted this study data and write most of the manuscript. TKi, KK, Al, SK, TKo, and $\mathrm{HN}$ contributed this course as faculty members. $\mathrm{JH}$ was contributed important and unique insight to the article. All authors read and approved the final manuscript.

\section{Acknowledgements}

We would like to thank Editage (www.editage.com) for editing and reviewing this manuscript for English language.

\section{References}

1. Zinski A, Blackwell KTCPW, Belue FM, Brooks WS. Is lecture dead? A preliminary study of medical students' evaluation of teaching methods in the preclinical curriculum. Int J Med Educ. 2017;8:32633.

2. Onishi H. History of Japanese medical education. Korean J Med Educ. 2018;30:283-94.

3. Densen P. Challenges and opportunities facing medical education. Trans Am Climatol Assoc. 2011;122:48-58.

4. Arai H, Ouchi Y, Toba K, Endo T, Shimokado K, Tsubota K, et al. Japan as the front-runner of superaged societies: Perspectives from medicine and medical care in Japan. Geriatr Gerontol Int. 2015;15:673-87.

5. Model Core Curriculum for Medical Education in Japan AY 2016 Revision Medical Education Model Core Curriculum Coordination Committee Medical Education Model Core Curriculum Expert Research Committee. 
6. McGaghie WC, Issenberg SB, Petrusa ER, Scalese RJ. A critical review of simulation-based medical education research: 2003-2009. Med Educ. 2010;44:50-63.

7. Cook DA, Hamstra SJ, Brydges R, Zendejas B, Szostek JH, Wang AT, et al. Comparative effectiveness of instructional design features in simulation-based education: systematic review and meta-analysis. Med Teac. 2013;35:e867-98.

8. Okuda Y, Bryson EO, DeMaria Jr S, Jacobson L, Quinones J, Shen B, et al. The utility of simulation in medical education: What is the evidence? Mt Sinai J Med. 2009;76:330-43.

9. Walsh S, Arnold B, Pickwell-Smith B, Summers B. What kind of doctor would you like me to be? Clin Teach. 2016;13:98-101.

10. Kerfoot BP, Nabha KS, Masser BA, McCullough DL. What makes a medical student avoid or enter a career in urology? Results of an international survey. J Urol. 2005;174:1953-7.

11. Kim S, Farrokhyar F, Braga LH. Survey on the perception of urology as a specialty by medical students. Can Urol Assoc J. 2016;10:349-54.

12. Jackson I, Bobbin $M$, Jordan M, Baker S. A survey of women urology residents regarding career choice and practice challenges. J Womens Health. 2009;18:1867-72.

13. Erzurum VZ, Obermeyer RJ, Fecher A, Thyagarajan P, Tan P, Koler AK, et al. What influences medical students' choice of surgical careers. Surgery. 2000;128:253-6.

14. Glass CC, Acton RD, Blair PG, Campbell AR, Deutsch ES, Jones DB, et al. American College of Surgeons/Association for Surgical Education medical student simulation-based surgical skills curriculum needs assessment. Am J Surg. 2014;207:165-9.

15. Tang KP, Chen CY, Wu MS, Chen TT, Wu BW, Tsai PF. Correlation between early clinical exposure environment, attitudes toward basic medicine, and medical students' basic science learning performance. BMC Med Educ. 2019;19:183.

16. Dornan T, Bundy C. What can experience add to early medical education? Consensus survey. BMJ. 2004;329:834.

17. Cook DA, Brydges R, Hamstra SJ, Zendejas B, Szostek JH, Wang AT, et al. Comparative effectiveness of technology-enhanced simulation versus other instructional methods: A systematic review and meta-analysis. Simul Healthc. 2012;7:308-20.

18. Lee JY, McDougall EM, Lineberry M, Tekian A. Optimizing the Timing of Expert Feedback During Simulation-Based Spaced Practice of Endourologic Skills. Simul Healthc. 2016;11:257-63

19. Pelaccia T, Viau R. Motivation in medical education. Med Teach. 2017;39:136-40.

20. Nomura K, Yano E, Aoki M, Kawaminami K, Endo H, Fukui T. Improvement of residents' clinical competency after the introduction of new postgraduate medical education program in Japan. Med Teach. 2008;30:e161-9.

21. Griffin B, Hu W. Parental career expectations: effect on medical students' career attitudes over time. Med Educ. 2019;53:584-92. 
22. Pianosi K, Bethune C, Hurley KF. Medical student career choice: a qualitative study of fourth-year medical students at Memorial University, Newfoundland. CMAJ Open. 2016;4:E147-52.

23. Head LK, Greene B, Gawad N, Hamstra SJ, Brandys T. Harvesting the 'SEAD': long-term follow-up of the surgical exploration and discovery program. J Surg Educ. 2020;77:96-103.

24. Ramaswamy RS, Fung D, Tiwari T, Foltz G, Akinwande O, Mokkarala $M$, et al. Factors influencing selection of an interventional radiology training program. Clin Imaging. 2019;57:30-34.

25. Coyan GN, D'Angelo MP, Kilic A, Gleason TG, Luketich JD, Aranda-Michel E, et al. Evaluation of a simulation-based mini-elective on medical student interest in cardiac surgery. J Card Surg. 2019;34:901-7.

26. Hicks KE, Doubova M, Winter RM, Seabrook C, Brandys T. Surgical exploration and discovery program: early exposure to surgical subspecialties and its influence on student perceptions of a surgical career. J Surg Educ. 2019;76:1248-57.

27. Zuccato JA, Kulkarni A. The impact of early medical school surgical exposure on interest in neurosurgery. Can J Neurol Sci. 2016;43:410-6.

28. Whiles BB, Thompson JA, Griebling TL, Thurmon KL. Perception, knowledge, and interest of urologic surgery: a medical student survey. BMC Med Educ. 2019;19:351.

29. Nguyen DD, Lee JY, Domes T, El-Sherbiny M, Andonian S, Franc-Guimond J, et al. Survey of Canadian urology programs: which aspects of the Canadian Residency Matching Service (CaRMS) application are the most important? Can Urol Assoc J. 2020;14.

30. Jayakumar N, Ahmed K, Challacombe B. Factors affecting UK medical students' decision to train in urology: a national survey. Minerva Urol Nefrol. 2016;68:409-16.

31. Kunanitthaworn N, Wongpakaran T, Wongpakaran N, Paiboonsithiwong S, Songtrijuck N, et al. Factors associated with motivation in medical education: a path analysis. BMC Med Educ. 2018;18:140.

\section{Figures}




\begin{tabular}{|c|c|c|c|c|c|c|c|c|c|c|c|c|}
\hline \multirow{2}{*}{ Start } & \multicolumn{4}{|c|}{1} & \multicolumn{4}{|c|}{2} & \multicolumn{4}{|c|}{3} \\
\hline & \multicolumn{2}{|l|}{$\mathrm{A}$} & \multicolumn{2}{|l|}{$\mathrm{C}$} & $\mathrm{A}$ & $\mathrm{B}$ & $\mathrm{C}$ & $\mathrm{D}$ & $\mathrm{A}$ & $\mathrm{B}$ & $\mathrm{C}$ & $\mathrm{D}$ \\
\hline 900 & \multicolumn{12}{|c|}{ Guidance \& Questionnaire } \\
\hline 930 & \multirow{2}{*}{\multicolumn{2}{|c|}{ Robotic surgery }} & \multirow{2}{*}{\multicolumn{2}{|c|}{$\begin{array}{l}\text { Single port dry box } \\
\text { 3D laparoscopy }\end{array}$}} & TUL & TUR & Cystoscope & PVP & \multirow{4}{*}{\multicolumn{4}{|c|}{ Laparoscopic surgery }} \\
\hline 1000 & & & & & PVP & TUL & TUR & Cystoscope & & & & \\
\hline 1030 & \multirow{2}{*}{\multicolumn{2}{|c|}{$\begin{array}{l}\text { Single port dry box } \\
\text { 3D laparoscopy }\end{array}$}} & \multirow{2}{*}{\multicolumn{2}{|c|}{ Robotic surgery }} & Cystoscope & PVP & TUL & TUR & & & & \\
\hline 1100 & & & & & TUR & Cystoscope & PVP & TUL & & & & \\
\hline 1130 & \multicolumn{12}{|c|}{ Rest \& transfer } \\
\hline 1200 & \multirow{4}{*}{\multicolumn{4}{|c|}{ Laparoscopic surgery }} & \multirow{2}{*}{\multicolumn{2}{|c|}{ Robotic surgery }} & \multirow{2}{*}{\multicolumn{2}{|c|}{$\begin{array}{l}\text { Single port dry box } \\
\text { 3D laparoscopy }\end{array}$}} & TUL & TUR & Cystoscope & PVP \\
\hline 1230 & & & & & & & & & PVP & TUL & TUR & Cystoscope \\
\hline 1300 & & & & & \multirow{2}{*}{\multicolumn{2}{|c|}{$\begin{array}{l}\text { Single port dry box } \\
\text { 3D laparoscopy }\end{array}$}} & \multirow{2}{*}{\multicolumn{2}{|c|}{ Robotic surgery }} & Cystoscope & PVP & TUL & TUR \\
\hline 1330 & & & & & & & & & TUR & Cystoscope & PVP & TUL \\
\hline 1400 & \multicolumn{12}{|c|}{ Rest \& transfer } \\
\hline 1430 & TUL & TUR & Cystoscope & PVP & \multirow{4}{*}{\multicolumn{4}{|c|}{ Laparoscopic surgery }} & \multirow{2}{*}{\multicolumn{2}{|c|}{ Robotic surgery }} & \multirow{2}{*}{\multicolumn{2}{|c|}{$\begin{array}{l}\text { Single port dry box } \\
\text { 3D laparoscopy }\end{array}$}} \\
\hline 1500 & PVP & TUL & TUR & Cystoscope & & & & & & & & \\
\hline 1530 & Cystoscope & PVP & TUL & TUR & & & & & \multirow{2}{*}{\multicolumn{2}{|c|}{$\begin{array}{l}\text { Single port dry box } \\
\text { 3D laparoscopy }\end{array}$}} & \multirow{2}{*}{\multicolumn{2}{|c|}{ Robotic surgery }} \\
\hline 1600 & TUR & Cystoscope & PVP & TUL & & & & & & & & \\
\hline 1630 & \multicolumn{12}{|c|}{ Transfer \& Questionnaire } \\
\hline $17: 30$ & \multicolumn{12}{|c|}{ Wrap up \& Closing remark } \\
\hline
\end{tabular}

\section{Figure 1}

Rotation schedule of medical students Students are divided into small groups of 2 or 3 students each, and they rotated through each procedure.

\section{Figure 2}

The schema of the arrangement of the training room and pictures of each procedure Small groups move around the room in a circle, spending 30 minutes at each station. 


\section{Likely score of each procedure}

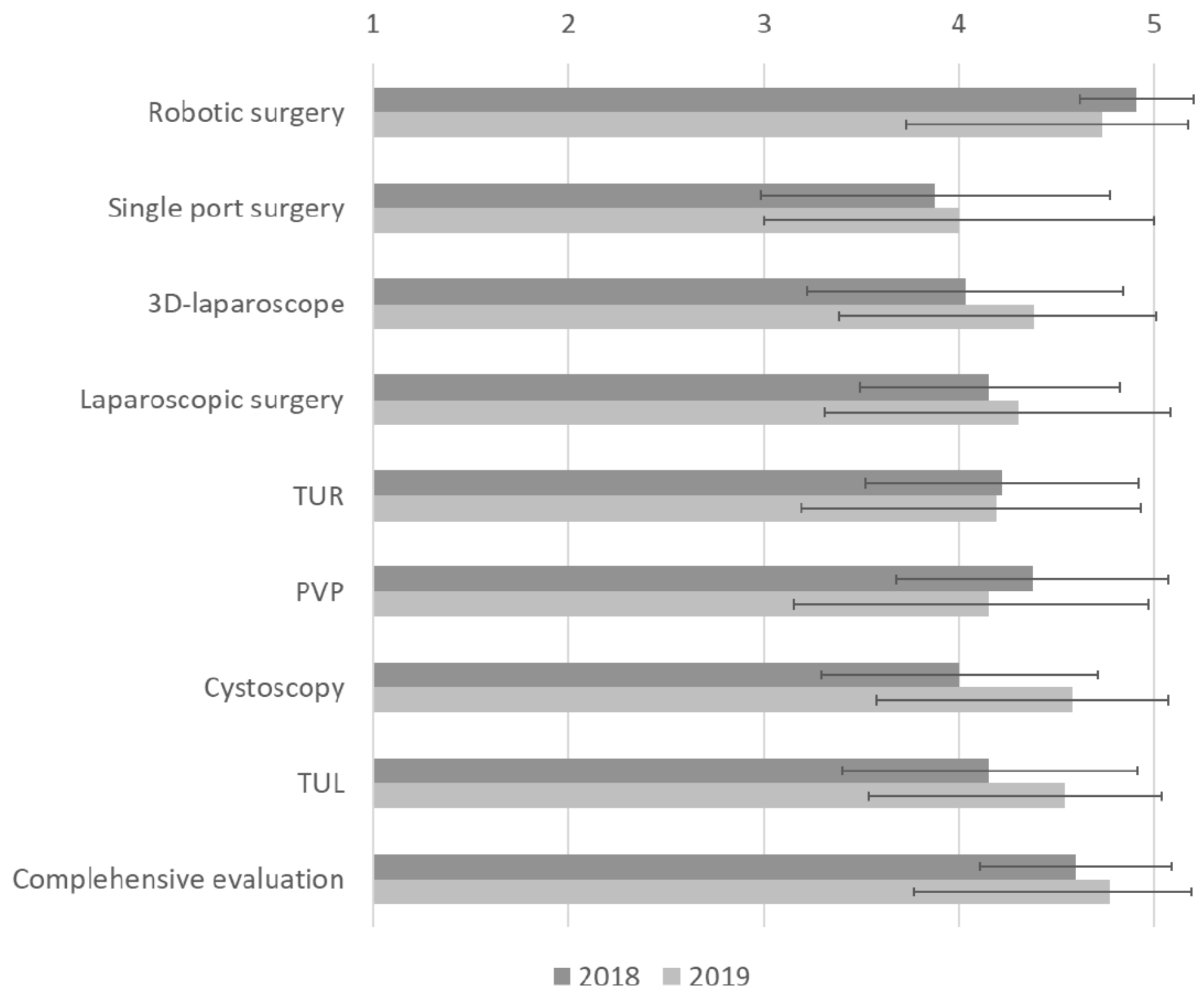

\section{Figure 3}

Likely scores of interest for surgery and urology before and after the course 
Interest in Surgery

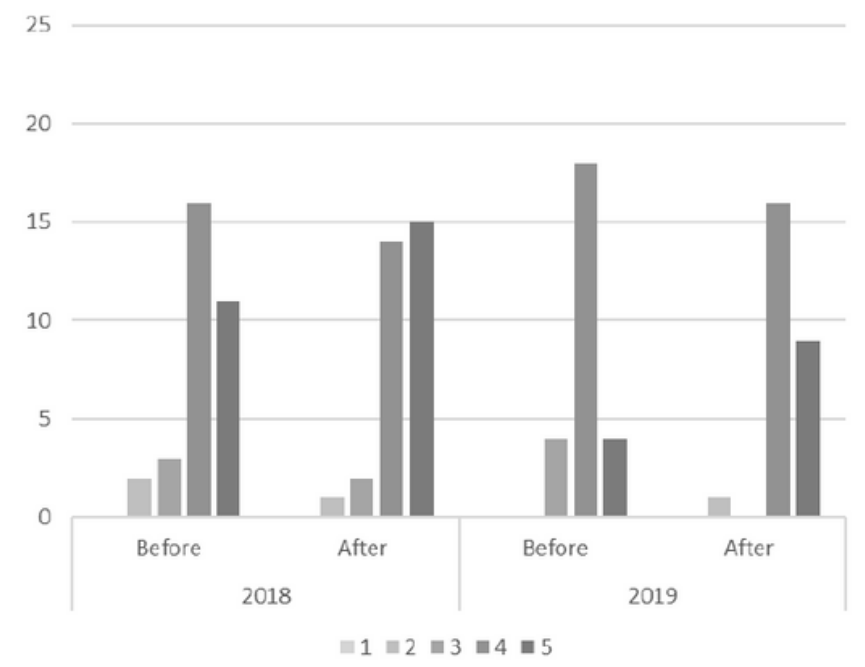

Figure 4

Likely scores in each course after the training

\section{Interest in Surgery}

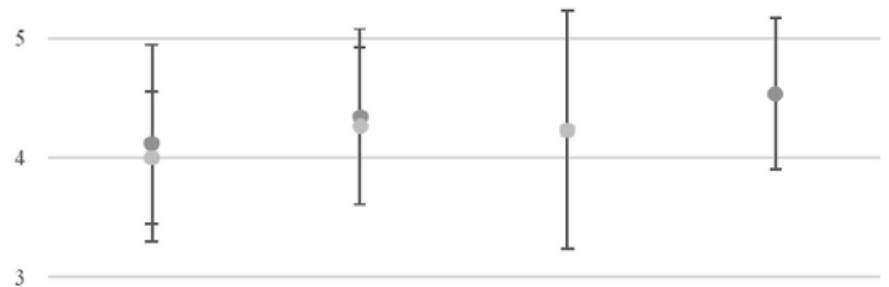

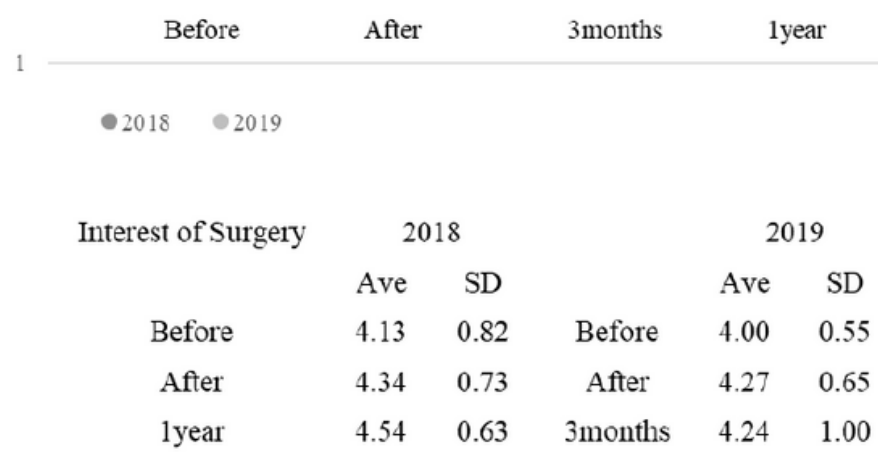

Interest in Urology

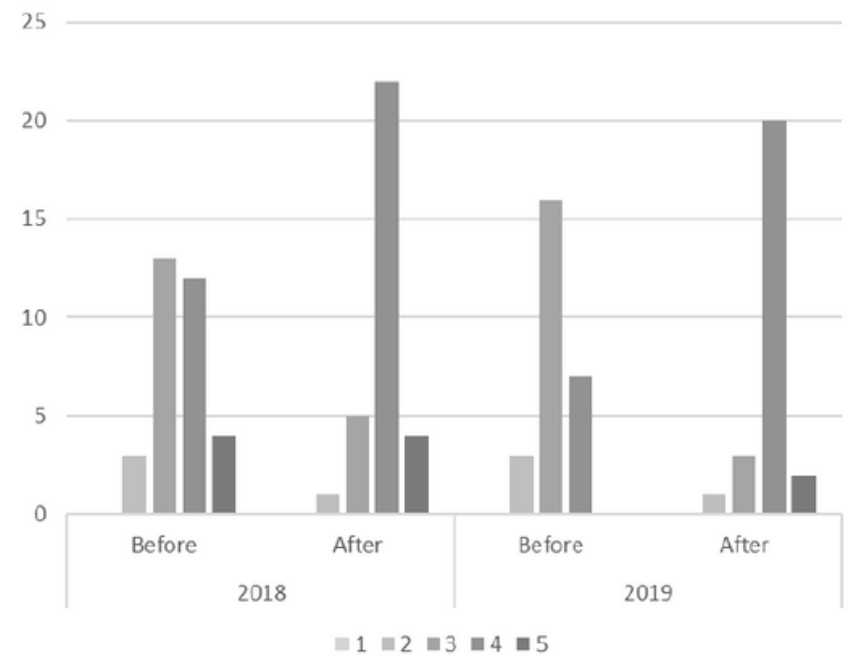

Interest in Urology

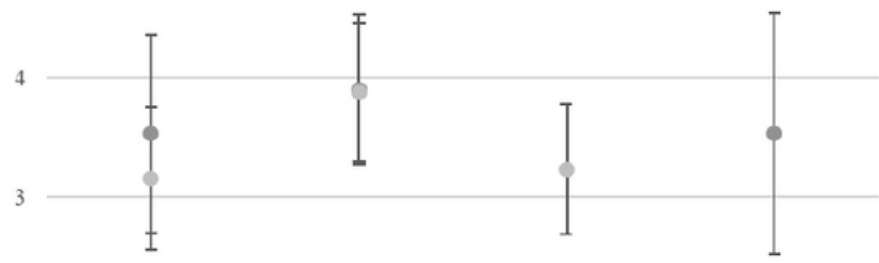

\begin{tabular}{cccccc} 
Interest of Urology & \multicolumn{2}{c}{2018} & & \multicolumn{2}{c}{2019} \\
& Ave & SD & & Ave & SD \\
Before & 3.53 & 0.83 & Before & 3.15 & 0.60 \\
After & 3.91 & 0.63 & After & 3.88 & 0.58 \\
lyear & 3.54 & 1.01 & 3months & 3.24 & 0.55
\end{tabular}

\section{Figure 5}


Time course of likely scores of interests for surgery and urology 